Bond University

Research Repository

\title{
Self-reported load carriage injuries of military soldiers
}

Orr, Robin Marc; Coyle, Julia; Johnston, Venerina; Pope, Rodney

Published in:

International Journal of Injury Control and Safety Promotion

DOI:

10.1080/17457300.2015.1132731

Link to output in Bond University research repository.

Recommended citation(APA):

Orr, R. M., Coyle, J., Johnston, V., \& Pope, R. (2017). Self-reported load carriage injuries of military soldiers. International Journal of Injury Control and Safety Promotion, 24(2), 189-197.

https://doi.org/10.1080/17457300.2015.1132731

\section{General rights}

Copyright and moral rights for the publications made accessible in the public portal are retained by the authors and/or other copyright owners and it is a condition of accessing publications that users recognise and abide by the legal requirements associated with these rights.

For more information, or if you believe that this document breaches copyright, please contact the Bond University research repository coordinator. 
Self-Reported Load Carriage Injuries of Military Soldiers

Running Title: Load Carriage Injuries of Military Soldiers

Robin Marc Orr, PhD (Corresponding author)

Tactical Research Unit

Bond University,

Gold Coast QLD 4229

Australia

Email: rorr@bond.edu.au

Phone: +61-7-5595 5444

Julia Coyle, PhD

School of Community Health

Charles Sturt University

PO Box 789

Albury NSW 2640

Australia

Email: JCoyle@csu.edu.au

Phone: +61-2-60519207

Venerina Johnston, PhD

School of Health and Rehabilitation Sciences,

The University of Queensland,

St Lucia, QLD 4072

Australia

Email: v.johnston@uq.edu.au

Phone: +61-7-3365 2124

Rodney Pope, PhD

Tactical Research Unit

Bond University,

Gold Coast QLD 4229

Australia

Email: rpope@bond.edu.au

Phone: +61-7-5595 5444

Conflicts of interest: All four authors acknowledge no conflicts of interest.

University Affiliation of Research: The University of Queensland

Location of research: Australian Army

Word Count: 4519 


\section{Abstract}

Objective: To investigate whether occupational load carriage constitutes a significant source of injury to military soldiers.

Methods: An online survey was sent to soldiers serving in specific Australian Army Corps known to experience the greatest occupational exposure to load carriage.

Results: Of the 338 respondents, $34 \%$ sustained at least one load carriage injury. Fifty-two percent of those injured during initial training reported sustaining an additional load carriage injury. The majority of injuries $(61 \%)$ were to the lower limbs with bones and joints the most frequently injured body structures (39\%). Endurance marching (continuous marching as part of a physical training session) was the activity accounting for most (38\%) injuries.

Conclusions: Occupational load carriage is associated with military soldier injuries and, once injured, soldiers are at a high risk of future load carriage injury. The bodily sites and nature of self-reported injuries in this study are akin to those of formally reported injuries and those of other militaries.

Keywords: load carriage, injury, injury prevention, military, weight load, marching 


\section{INTRODUCTION}

2 People undertake load carriage activities for a wide variety of reasons. Recreationally, hikers

3 undertake walks with loads of up to $29 \%$ of their body weight for enjoyment or personal

4 challenge (1). Conversely, as part of their activities of daily living and for survival, African

5 women can carry loads of up to $70 \%$ of their body weight on their heads $(2,3)$. Vocationally,

6 hired porters carry loads of up to a staggering $183 \%$ of their body weight in along trails and

7 into mountain regions (4-6). In tactical populations, fire fighters carry loads of up to $37 \mathrm{~kg}$

8 made up of various forms of breathing apparatus, protective clothing, and firefighting

9 equipment $(7,8)$. Likewise, general and specialist police officers can carry loads of up to 22

$\mathrm{kg}$ (9) while dealing with uncooperative and potentially aggressive offenders. However, perhaps the most well know load carrier is the military soldier.

From the Assyrian spearmen of antiquity to the modern combat troops of today, soldiers are required to carry external loads comprised of items and equipment for sustainment (like food and water), protection (like shields and body armour) and lethality (like spears and rifles) (10). With this requirement to carry load, soldiers have likewise sustained injuries throughout history when carrying these loads (11).

Circa 400 BC, the long marches of Cyrus' infamous 10,000, an army of Greek mercenaries accompanied by Xenophon, were thought to suffer from stress fractures, torn ligaments, muscle damage, blisters and abrasions (12). While some of these injuries may be considered minor against today's treatments, for the Cyrean soldier it was life or death as they hobbled to keep up with the moving army. More recent literature has likewise associated load carriage tasks with a variety of injuries to soldiers ranging from fractures to ligamentous damage and skin blistering (13). 
Existing studies of injury patterns in military load carriage have, however, been based on single events (14-17). What is not known is the pattern of load carriage injuries occurring across a prolonged period, such as a soldier's career. Thus, the aim of this study was to determine whether contemporary military load carriage constitutes a significant source of injury to soldiers within the Australian Regular Army (ARA) during their military careers and, if so, to determine the profile of these injuries.

\section{METHODS}

\section{Participants}

Units within selected corps were invited to participate in the study. These corps, identified and selected via purposive sampling (sampling within a targeted group), were the Royal Australian Infantry, Royal Australian Artillery, Royal Australian Engineers, Royal Australian Armoured Corps, and the Royal Australian Corps of Signals. Soldiers within these trades of the Australian Defence Force were specifically selected as they experience the greatest occupational exposure to load carriage $(18,19)$. All personnel posted to the selected units at the time of this study were invited to participate subject to the following inclusion criteria: 1) a member of the ARA, 2) posted to one of the selected units, and 3) in full time service.

\section{Survey Design}

As in previous load carriage research $(1,16,20,21)$, a survey approach was also used in this research. A key benefit of employing a survey approach is that it can capture information 
directly from the relevant people (22), in this instance ARA soldiers serving in various locations across Australia and overseas. An online survey questionnaire was designed in accordance with the evidence-based recommendations of Parsons (23).

The survey questions were designed by the investigators, specifically catering for the military environment, context and terminology, and used to inform several load carriage projects (24). Prior to administering the survey, two pilot surveys were conducted to increase reliability (22). The final online questionnaire consisted of 22 questions, grouped into six sections, allowing for up to 135 responses. This study reports the findings from questions relating to load carriage injuries as they relate to the survey demographic data.

\section{Data Collection}

Data were collected via an online survey questionnaire hosted by SurveyMonkey, an independent online survey provider (25). Respondents were allowed to interrupt and then reenter the survey (26). However, respondents were only able to complete and submit their online questionnaire once (27). Concerns that the online questionnaire might be impacted upon by accessibility to the survey tool by the general population $(26,27)$ were mitigated by the need for each respondent to log into the Defence Restricted Network to access the link to the online questionnaire over a six to eight week period depending on unit availability. The research was sponsored by the Australian Defence Force Joint Health Command. Command support for the research was provided by Forces Command. Ethics approval for the research was granted by the Australian Defence Human Research Ethics Committee, and the Behavioural and Social Sciences Research Ethics Committee of the University of Queensland. 
Data Extraction and Analysis

\section{Results \\ RESULTS}

Unit cooperation and survey response rate calculations were based on methods recommended by the Institute for Social and Economic Research (28) and the American Association for Public Opinion Research (AAPOR) (29). Unit cooperation rates were defined as the percentage of units, from those identified and approached, that were willing to participate, and included consideration of those units that declined to participate and those units from which no further contact was received by the investigator. Survey response rates were defined as the percentage of personnel invited to participate in the survey who met the criteria of having completed the survey (ie completed over $80 \%$ of questions) or partially completed the survey (ie completed $51 \%$ to $80 \%$ of questions). Survey response rates were adjusted for anticipated errors via the formula recommended by AAPOR (29). Anticipated errors included disruption to internet services and invitation emails being captured in spam filters. The anticipated error rate as determined was estimated at $10 \%$ based on feedback from units.

Analysis of variance (ANOVA) was employed to compare data (load weights carried) between three or more groups (types of injuries) and if significant, Bonferroni post-hoc tests for multiple comparisons were used to determine where the differences lay. Data were analysed using the IBM Statistical Package for the Social Sciences (SPSS) Statistics Version 19.0 for Macintosh and Windows (30) with the alpha level set at 0.05 . 
Of the 30 units approached, eight units agreed to participate in the study, two units declined situated under its umbrella of command. The investigators received no responses from the remaining 13 units. On this basis, unit cooperation rate was calculated as $27 \%(\mathrm{n}=8)$, unit refusal rate as $30 \%(n=9)$ and unit non-contact rate as $43 \%(n=13)$.

With eight Army units willing to engage in the research, an invitation to participate in the survey was sent, by email, to an estimated 1,793 defence email addresses for personnel posted to these units. This figure is based on the number of personnel posted to the units. Discussions with units, who sent out the invitations by email, confirmed that the email invitations were sent out to group lists and did not exclude personnel who might have been on leave, detached to other units, on training courses, or on deployment, and hence would not have received the emailed invitation during the survey period.

A total of 380 personnel commenced the online survey, completing demographic data (Questions 1 and 2). Of these respondents, completion rate was $88 \%$ ( $\mathrm{n}=333)$, partial completion rate as $1 \%(n=5)$, and 'break off' rate as $11 \%(n=42)$. This provided a total of 338 personnel data sets for analysis. The survey response rate was then determined as $19 \%$. With this in mind, if a conservative $10 \%$ anticipated error rate is allocated in response to the survey dissemination concerns identified above, the adjusted response rate would be calculated as $21 \%$. This response rate is equivalent to a previous ADF survey (31) and similar to those for surveys in foreign military forces (32). All complete responses were utilised in the analysis, with partial responses also included where possible (i.e. when responses to a question being analysed contained the required data). 
Of the 338 respondents, $22(7 \%)$ were female. The female respondents ranged in age from 20 to 46 years $(\mathrm{M}=31.6 \pm 8.0$ years $)$, in height from 1.53 to $1.76 \mathrm{~m}(\mathrm{M}=1.66 \pm 0.78 \mathrm{~m})$, and in body weight from 52 to $80 \mathrm{~kg}(\mathrm{M}=66.8 \pm 7.7 \mathrm{~kg})$. The male respondents $(93 \%, \mathrm{n}=316)$ ranged in age from 18 to 56 years $(M=31.5 \pm 7.6$ years), in height from 1.50 to $2.00 \mathrm{~m}(\mathrm{M}=1.80 \pm 0.73$ $\mathrm{m})$ and in body weight from 60 to $126 \mathrm{~kg}(\mathrm{M}=85.5 \pm 11.1 \mathrm{~kg})$. The median length of service was 9.5 years, ranging from one to over 25 years. The demographic characteristics of survey respondents are further detailed in Table 1.

\section{Frequency and Distribution of Self-Reported Load Carriage Injuries} carriage event at some stage during their military career. Eight percent $(n=9)$ of the respondents who reported an injury were female soldiers and $92 \%(n=107)$ were male soldiers. This gender both reinjured the same site and suffered an injury to another body site. suffering at least one load carriage injury during initial training. Of these 56 respondents, $32 \%$ $(\mathrm{n}=18)$ reported sustaining an additional injury (to the same or another body site) within the 
initial training reported sustaining an additional injury (to the same or another body site) at some time during their career. The distributions across time of the self-reported load carriage injuries sustained by survey respondents are shown in Figure 1.

Insert figure 1 approximately here

\section{Body Sites of Self-Reported Load Carriage Injuries}

Overall, $61 \%(n=118)$ of the self-reported load carriage injuries were to the lower limbs, $27 \%$ $(n=52)$ of injuries were to the back, $9 \%(n=18)$ of injuries were to the upper limbs, $3 \%(n=5)$ were to the abdomen and hip and $1 \%(n=1)$ was to the head. Of these injuries the lower leg $(n=46,24 \%)$ and lower back $(n=45,23 \%)$ were the leading body sites of self-reported injury (see Figure 2).

\section{Nature of Self-Reported Load Carriage Injuries}

Bones and joints were the most frequently injured body structures (39\% of injuries, $n=76$ ), and another third of injuries were reportedly to muscles and tendons $(36 \%, n=70)$. Ligaments accounted for an additional $15 \%$ of injuries $(n=29)$, followed by 'other' structures $(6 \%, n=12)$.

Skin (being foot blisters) accounted for the remaining injuries $(4 \%, n=7)$. Overall, soft tissue injuries constituted $55 \%$ of the self-reported injuries $(n=106)$ (see Figure 3$)$.

The mean self-reported load carried by respondents at the time of injury was $29.5 \mathrm{~kg}$ ( $\pm 13.6 \mathrm{~kg}$ ), ranging from 3 to $75 \mathrm{~kg}$. Considering this finding, an one-way ANOVA found no significant differences between groups of injuries formed on the basis of which structures were 
injured in relation to the mean self-reported loads carried by the injured respondents at the time of injury $(\mathrm{F}(4,186)=2.03, \mathrm{p}=0.92)$.

\section{Activities Conducted at the Time of the Self-Reported Load Carriage Injuries}

Field training exercises reportedly accounted for $28 \%(n=55)$ of load carriage injuries and physical training (PT) a further 14\% $(n=27)$. Endurance marching, which can be conducted as part of PT or a field training exercise, accounted for the highest frequency of load carriage injuries $(38 \%, n=73)$. 'Other' activities accounted for the remaining $20 \%$ of injuries $(n=39)$.

The majority (86\%: $n=6$ ) of foot blisters occurred during endurance marching, while field exercises accounted for $40 \%(n=12)$ of ankle injuries occurring during load carriage.

\section{Discussion}

The aim of this study was to investigate load carriage injuries sustained and reported by ARA soldiers. The study found that load carriage has the potential to cause a variety of soldier injuries. Just over a third (34\%) of survey respondents reported suffering at least one injury while undertaking load carriage activities during their military careers. The mean self-reported loads carried by the survey respondents at the times when load carriage injuries occurred was $29.5 \mathrm{~kg}$. The majority of the reported injuries involved either the lower limb or back, with bones and joints accounting for the most frequently reported body structures injured. Endurance marching was the leading activity being performed at the time that load carriage injuries occurred with endurance marching also occurring during field activities and PT.

The figures reported in this study are proportionally lower than the lifetime injury experiences of the 702 survey respondents reported having experienced an injury while hiking, at some 
time in their lives. A potential reason for this higher lifetime frequency of reported injuries in the hiking population might be their exposure to load carriage events, as measured by total years of exposure, and frequency and duration of events within exposed years. Previously presented research indicated that the majority (66\%) of Australian Army load carriage events last less than 3 hours with few (33\%) lasing for more than six hours (33) in their latest single day load carriage event. Conversely, the hiking population surveyed by Lobb (1) included $2 \%$ of respondents who claimed to carry their loads for less than 2 hours per day when hiking, 39\% who carried a load for 2 to 5 hours per day and 59\% who carried loads for over 5 hours per day. Of these hiking respondents, $43 \%$ reported carrying loads for a single day when hiking, $47 \%$ reported carrying loads for 2 to 3 days, and $10 \%$ reported load carriage for 4 to 8 days.

Despite these differences, in the absence of further comparable data on the exposure of both military respondents and hikers to load carriage over their lifetimes, it is impossible to estimate the level to which differential exposure might have contributed to the difference between these populations in load carriage injury frequencies. Differences between the two populations in distribution of demographic factors (such as nationality, age, and fitness) and the nature of the activity (terrain and speed of movement as examples) may have also contributed to the differences in injury findings. While it may appear that non-military load carriage activities, like hiking, may suffer a higher proportion of lifetime injuries when compared to military load carriage, these results should be viewed with caution as the severity of the injuries and injury reporting thresholds are not known.

The injury frequency figures from this study were reasonably consistent with the figures reported for military load carriage events in US military forces by Knapik, et al. (14) and Reynolds, et al. (15). The observed frequency of injury experiences during military load carriage reported in this current study (116 respondents of the 338 survey respondents) was 
based on soldier experiences of load-carriage injuries across their whole career. On the other hand, Knapik, et al. (14) reported a $24 \%$ injury incidence rate (79 soldiers of 335 soldiers injured) for infantry soldiers carrying a load of $46 \mathrm{~kg}$ on a 20-km maximal effort load.

Injury body site data from this study corresponds with injury body site findings within both specific load carriage studies $(14,15)$ and studies of general military training (34-36), suggesting consistency across contexts of load carriage, as well as across time. In the current study, the lower limbs were attributed with the highest reported proportions of self-reported injuries (61\%). A high proportion of lower leg injuries is consistent with findings of previous studies of single load carriage events $(14,15)$, of military personnel in general (34-36), of ADF personnel specifically (37), and of recreational hikers over a period of time (1).

In the aggregated injury body site data, the back was associated with the second highest proportion of reported injuries ( $23 \%$ of all injuries). Given the biomechanical impacts of load carriage on the spine, such as increased lumbar compression and shear forces, changes to thoraco-pelvic rhythm and increased forward lean (38-41), the high proportion of lower back injuries was not unexpected. A study by Knapik et al. (14) likewise identified the lower back as the second highest body site of injury. However, in their study of a single load carriage event, the back was the leading site of injury which led to the soldier's inability to complete the march.

Ankle injuries in this study represented $16 \%$ of all reported injuries. The study of Lobb (1), which similarly reported injuries sustained over time and collected by survey, found the ankle was the body site of $28 \%$ of all injuries reported by New Zealand hikers. Conversely, studies reporting injuries sustained during a specific load carriage event have observed a notably lower 
proportion of ankle injuries $(14,15)$. In the study of Knapik, et al. (14), $6 \%$ of all injuries were determined to be ankle and knee sprains. Similarly, Reynolds, et al. (15) reported 5\% of all injuries were injuries to the ankle. A potential reason for these differences in injury site proportions comes from the contextual environments of the studies. With the actual nature of terrain traversed by the New Zealand hikers not described in the study by Lobb (1), the studies of Knapik, et al. (14) and Reynolds, et al. (15) noted the load carriage event was in each case conducted on formed roads or dirt paths during a single marching event. Conversely, the results of this study captured incidents across all terrains during events ranging from endurance marching to patrolling.

Previous literature has identified blisters as the primary concern for military marching $(42,43)$. In the current study, $4 \%$ of self-reported injuries were due to foot blisters. These proportions of foot blister injuries are similar to those observed by Lobb (1) (6.8\%) although notably lower than the proportions reported by Knapik, et al. (14) and Reynolds, et al. (15), being between $32 \%$ and $48 \%$ of all reported injuries. Several potential reasons for these differences in blister proportions exist, including reporting practices, differences in the nature of load carriage activities and study methods, and additional risk factors. Data capture in the current study was achieved through self-reports of load carriage injuries over a service period rather than immediately after a single event. Furthermore, soldiers themselves might not consider blisters to be an injury or an injury serious enough to seek medical attention (14) and, as such, few soldiers might have listed foot blistering as an injury in the current survey. The same reasoning could apply to the lower proportion of blister injuries identified by Lobb (1). Finally, the study methods of Knapik, et al. (14) and Reynolds, et al. (15) provided a greater opportunity to capture data on blister injuries, with their studies including some measure of active medical assessments following the load carriage events. Medical staff documented injuries during or 
immediately following the march; thus respondents were not asked to remember suffering a

blister at some time during their military career (as in the current study) or during their years of hiking (1).

While endurance marching alone was the activity accounting from the most injuries, this activity can be conducted as part of both field training exercises and PT. Considering this, field training exercises, rather than PT, constituted the activity type most often associated with load carriage injuries. Overall, $28 \%$ of survey respondents identified field training exercises as the activity type at the time of injury, with PT identified by $14 \%$. Potential reasons for this higher frequency of injury occurring during field training exercises include differences between the two activities in the amounts of time that soldiers were exposed to them and in the respective load carriage contexts. Moreover, PT lessons are commonly conducted by PT Instructional (PTI) staff, trained in depth in the safe conduct of physical activity. PTI staff are trained to monitor participants for signs of fatigue, illness and injury - monitoring that forms part of the ARA's injury prevention strategy for injuries sustained during physical activity (37). As such, PTIs may have anticipated and prevented some instances of potential load carriage injuries during PT sessions.

Previous research by Orr et al. (44) has noted significantly heavier loads reportedly carried during field training exercises when compared to those carried by soldiers during PT. Furthermore, that study identified differences in the nature of the terrain covered during these two activities, with field training exercises typically conducted through light bush over mild or steep hills while PT was more frequently conducted on roads or on dirt or grass over flat terrains. On this basis, both the heavier loads and the more challenging terrain may have induced the higher frequency of injuries reported for field training exercises. The differences in terrain may also account for the higher frequency of ankle injuries reported for field training 
exercises $(40 \%)$ than for PT (10\%), given that uneven terrain is a risk factor for ankle injury $(45)$

Nearly half $(48 \%)$ of the self-reported injuries occurring during load carriage activities occurred during initial training. This result suggests a potential impact on ARA force generation capacity, especially when considering that some trainees may have been injured to the extent that they did not complete training and as such could not report their injuries in this study. While not specific to load carriage, the literature does suggest that rates of musculoskeletal injuries are higher during the earlier weeks of military training, when untrained recruits are adapting to an increase in exercise (46-50). Proposed causal mechanisms for these injury patterns vary. Stein, et al. (51) considered the onset of basic training to be the key causal injury factor, rather than a cumulative effect of marching mileage. Knapik, et al. (52), who observed all activities completed during training days, found that US Army Basic Combat trainees covered an estimated $11 \mathrm{~km} /$ day during the first of three training phases. Thus, the commencement of training itself can be linked with cumulative loading. Further evidence has found trainee injury rates to be highest during training weeks with the highest volume of physical training (34). With basic military training typically escalatory in nature, both the sudden commencement of training and the continuous and progressive volume of conditioning as part of the training may combine to over-tax the musculoskeletal system to a point where any additional increases in volume dramatically increase the chance of injury.

A final force generation consideration lies in the impact of load carriage injuries. Even if the severity of a load carriage injury does not warrant a medical discharge from training for the soldier and thus result in the loss of a potential future soldier for the ARA, an injury during training has the potential to delay the soldier's training while rehabilitation occurs and, due to lost training time, to reduce force generation capability (34). 
The consequences of injuries sustained during initial training flow on to impact upon soldiers in their unit, and upon ARA force maintenance. Of the personnel who reported sustaining an injury during initial training, 52\% reported at least one additional injury (32\% suffered an additional injury within 12 months). Regardless of initial injury presentation, $42 \%$ of respondents reported suffering subsequent injuries during load carriage activities, either to the same body site (43\%), an additional body site (31\%), or both the same and an additional body site $(27 \%)$. These results suggest that soldiers who suffer an injury during a load carriage activity are at a notable risk of sustaining additional load carriage injuries.

These injuries impact directly on the soldier's readiness and on force maintenance through the reduction in available deployable personnel (34). A study of U.S. army personnel by Jennings, et al. (35), identified that $80 \%$ of soldiers suffering an injury were unable to undertake load carriage activities. On this basis, soldiers who have suffered an injury (be it from a load carriage activity or another mechanism) may be unable to carry load while they recover. In an ARA context, injury may prevent the soldier from being able to complete force readiness assessments $(53,54)$. For soldiers, such limitations in ability to carry load and to pass force readiness assessments have downstream effects on their ability to deploy. For the ARA, this will result in a reduction in deployable force size, and hence also in force maintenance capability.

In the face of the resulting reduction in deployable force size, deployed soldiers may be required to conduct additional patrols to fill the capability gap created by injured soldiers who cannot be replaced due to reduced deployable force reserves. Thus, their exposure to the load carriage event would then be increased. Alternatively, the patrol size could be reduced in order to limit the requirement for soldiers to undertake additional patrols. In that case, with the 
remaining soldiers are still required to carry all the additional stores required of a patrol (like radios, batteries, specialist weapons), and so these remaining soldiers would be required to carry heavier loads. This increased load in turn increases the risks to the soldier associated with the carriage of heavier loads (13). Furthermore, if injured soldiers are not on patrols, unit fire power may be reduced as each soldier is effectively a weapon platform. Thus, the remaining soldiers on patrol may be more vulnerable to enemy action. This vulnerability may be increased by the reduction in mobility, lethality and attention to task associated with heavy load carriage (13).

\section{LIMITATIONS}

A major limitation was the inability to account for the precise number of soldier solicited due to temporary attachments, detachments, and leave. In addition, as the survey covered the soldier's entire careers, recall bias may have been present and potentially minor injuries like blisters may not have been accurately recalled.

\section{CONCLUSION}

The findings of the current study suggest that load carriage presents a credible source of risk to Australian soldiers by increasing their vulnerability to injury, combat wounding and even potential fatality during military operations due to reductions in personnel numbers and levels of combat performance brought about by the occurrence of injuries during load carriage. A notable number of injuries, akin to those sustained by other military forces, were attributed to soldier load carriage. For any military organisation these injuries have consequences that range from lost working days for recovery and rehabilitation to increased risk of future injury and hence an ongoing pattern of injury, recovery and rehabilitation. Further, generation and 
maintenance of a military workforce may be impaired, with fewer soldiers able to carry loads

380 and able to meet with the physical requirements for operational deployment if injury rates are

381 high. During military operations, reduced force numbers, caused by load carriage injuries, can

382 increase the load carriage exposure of other soldiers, through requirements to increase patrols

383 to fill in for a missing capability. 
1 Lobb B. Load carriage for fun: a survey of New Zealand trampers, their activities and injuries. Appl Ergon. 2004;35(6):541-7. loaded carriers under controlled conditions of load and speed. Ergonomics. 1989;32(12):1539-50. 3 Heglund NC, Willems PA, Penta M, Cavagna GA. Energy-saving gait mechanics with head-supported loads. Nature. 1995;375(6526):52-4.

4 Bauer I. Inca trail porters: the health and local tourism employees as a challenge for travel medicine. Journal of Travel Medicine. 2003;10(2):94-9.

5 Bastien GJ, Schepens B, Willems PA, Heglund NC. Energetics of load carrying in Nepalese porters. Science. 2005;308(5729):1755.

3966 Malville NJ, Byrnes WC, Lim HA, Basnyat R. Commercial porters of eastern Nepal: health status, physical work capacity, and energy expenditure. Am J Hum Biol. 2001;13(1):44-56.

7 Park K, Hur P, Rosengren KS, Horn GP, Hsiao-Wecksler ET. Effect of load carriage on gait due to firefighting air bottle configuration. Ergonomics. 2010;53(7):882-91. 8 Richmond VL, Rayson MP, Wilkinson DM, Carter JM, Blacker SD. Physical demands of firefighter search and rescue in ambient environmental conditions. Ergonomics. 2008;51(7):1023-31. 9 Carlton SD, Orr R, Stierli M, Carbone PD. The impact of load carriage on mobility and marksmanship of the tactical response officer. Journal of Australian Strength and Conditioning. 2013;22(1):23-7.

10 Orr R. The History of the Soldier's Load. Australian Army Journal. 2010;VII(2):67-88.

11 Orr R, Johnston V, Coyle J, Pope R. Reported Load Carriage Injuries of the Australian Army Soldier. Journal of occupational rehabilitation. 2014;25:316-22.

12 Lee JWI. A Greek Army on the March: Soldiers and Survival in Xenophon's Anabasis. New York: Cambridge University Press; 2007.

13 Knapik JJ, Reynolds KL, Harman E. Soldier load carriage: historical, physiological, biomechanical, and medical aspects. Mil Med. 2004;169(1):45-56.

14 Knapik JJ, Reynolds KL, Staab J, Vogel JA, Jones B. Injuries associated with strenuous road marching. Mil Med. 1992;157(2):64-7.

15 Reynolds KL, White J, Knapik JJ, Witt C, Amoroso P. Injuries and risk factors in a 100-mile (161-km) infantry road march. Preventative Medicine. 1999;28(2):167-73.

16 Birrell SA, Hooper RH. Initial subjective load carriage injury data collected with interviews and questionnaires. Mil Med. 2007;172(3):306-11.

17 Reynolds KL, Kaszuba J, Mello RP, Patton JF. Prolonged treadmill load carriage: acute injuries and changes in foot anthropometry: No. USARIEM-T1-91. Natick: MA: United States Army Research Institute of Environmental Medicine; 1990.

18 Australian Army. Combat Fitness Handbook. Land Warfare Publication - General 7-7-4. 2005. 19 Orr R, Pope R, Coyle J, Johnston V. Occupational Loads Carried by Australian Soldiers on Military Operations. Journal of Health Safety and the Environment. 2015;31(1):451-67.

20 Birrell SA, Haslam RA. The effect of military load carriage on 3-D lower limb kinematics and spatiotemporal parameters. Ergonomics. 2009;52(10):1298-304.

21 Legg SJ, Perko L, Campbell P. Subjective perceptual methods for comparing backpacks. Ergonomics. 1997;40(8):809-17.

22 Fink A. How to conduct surveys: A step-by-step guide. 3rd Edition. Thousand Oaks:CA: SAGE; 2005.

23 Parsons C. Web-based surveys: Best practices based on the research literature. Visitor Studies. 2007;10(1):13-33.

24 Orr R. Soldier load carriage: A risk management approach. Australia: The University of Queensland; 2013. 
26 Schonlau M, Ronald Jr D, Elliott MN. Conducting research surveys via e-mail and the web: Rand

436 Corporation; 2002.

43727 Ritter L, Sue V. Conducting online surveys. Los Angeles: Sage Publications; 2007.

43828 Lynn P, Roeland B, Johanna L, Jean M. Recommended Standard Final Outcome Categories and

439 Standard Definitions of Response Rate for Social Surveys. Working Papers of the Institute for Social

440 and EconomicResearch. 2001;paper 2001-2003.

44129 The American Association for Public Opinion Research. Standard Definitions: Final Dispositions of

442 Case Codes and Outcome Rates for Surveys. 7th editiion: AAPOR; 2011.

44330 SPSS Inc.: Statistical Package for the Social Sciences (Version 20) [computer software]. IBM

444 Corporation; 2010.

44531 Directorate of Strategic Personnel Policy Research. The first Australian Defence Force Families

446 Survey. Australian Defence Force, Commonwealth of Australia. 2009.

44732 Moradi B. Interpreting Response Rate for the 2010 Department of Defence Complrehensive Review Survey: A Research Memo. Palm Center, University of California. 2010.

33 Orr R. The Australian Army load carriage context: A challenge for defence capability. Annual

450

451

452 Military Pharmacy Specialist Interest Group conference Brisbane: Australia; 2012.

34 Almeida S, Williams K, Shaffer R, Brodine S. Epidemiological patterns of musculoskeletal injuries and physical training. Medicine \& Science in Sports and Exercise. 1999;31(8):1176-82.

35 Jennings BM, Yoder LH, Heiner SL, Loan LA, Bingham MO. Soldiers With Musculoskeletal Injuries. Journal of Nursing Scholarship. 2008;40(3):268-74.

36 O'Connor F. Injuries during Marine Corps officer basic training. Mil Med. 2000;165(7):515-20.

37 Defence Health Services Branch. ADF Health Status. Defence Health Services Branch: Department of Defence. 2000.

38 Meakin JR, Smith FW, Gilbert FJ, Aspden RM. The effect of axial load on the sagittal plane curvature of the upright human spine in vivo. J Biomech. 2008;41(13):2850-4.

46039 Fowler NE, Rodacki AL, Rodacki CD. Changes in stature and spine kinematics during a loaded 461 walking task. Gait \& Posture. 2006;23(2):133-41.

46240 Attwells R, Birrell SA, Hooper RH, Mansfield NJ. Influence of carrying heavy loads on soldier's posture, movements and gait. Ergonomics. 2006;49(14):1527-37.

41 Majumdar D, Pal MS. Effects of military load carriage on kinematics of gait. Ergonomics. 2010;53(6):782-91.

42 Reynolds KL. Injuries and risk factors in an 18-day Marine winter mountain training exercise. Mil Med. 2000;165(12):905-10.

43 Knapik JJ, Reynolds KL, Duplantis KL, Jones B. Friction Blisters: Pathophysiology, Prevention and Treatment. Sports Medicine. 1995;20(3):136-47.

44 Orr R, Pope R, Johnston V, Coyle J. Soldier load carriage: An investigation into the load carriage conditioning practices of the Australian Regular Army. Australian Military Medicine Association (AMMA) conference: Coming of age; 2012; Brisbane: Australia 2012.

45 Chan K, Yuan Y, Li C, Chien P, Tsang G. Sports causing most injuries in Hong Kong. British Journal of Sports Medicine. 1993;27(4):263.

46 Greaney RB, Gerber FH, Laughlin RL, et al. Distribution and Natural History of Stress Fractures in U.S. Marine Recruits. Radiology. 1983;146:339-46.

47 Pester S, Smith PC. Stress fractures in lower extremities of soldiers in basic training. Orthop Rev. 1992;21(3):297-303.

48 Milgrom C, Giladi M, Stein M, et al. Stress fractures in military recruits. British Editorial Society of Bone and Joint Surgery. 1985;67 B(5):732 - 5.

49 Sheehan KM, Murphy MM, Reynolds KL, Creedon JF, al. e. The response of a bone resorption marker to Marine recruit training. Mil Med. 2003;168(10):797-801.

50 Bush RA, Brodine S, Shaffer R. The Association of Blisters with Musculoskeletal Injuries in Male Marine Recruits. J Am Podiatr Med Assoc. 2000;90(4):194-8. 
51 Stein M, Shlamkovitch N, Finestone A, Milgrom C. Marcher's digitalgia paresthetica among

486 recruits. Foot Ankle. 1989;9(6):312-3.

48752 Knapik JJ, Darakjy S, Hauret KG. Ambulatory physical activity during United States army basic 488 combat training. International journal of sports medicine. 2007;28(2):106-15.

48953 Australian Army. DI(A) OPS 80-1 AMDT4: Army Individual Readiness Notice: Department of 490 Defence: Australian Government; 2008.

49154 Defence Science and Technology Organisation. Physical Standards for Military Service to be 492 Benchmarked. Media Release 043/2009 2009.

493

494 
Table 1: Demographic characteristics of respondents

\begin{tabular}{|c|c|c|c|c|c|}
\hline Corps & $\begin{array}{c}\text { Number } \\
n\end{array}$ & $\begin{array}{c}\text { Age (y) } \\
M(S D) \\
\text { Range }\end{array}$ & $\begin{array}{c}\text { Weight (kg) } \\
M(S D) \\
\text { Range }\end{array}$ & $\begin{array}{c}\text { Height }(\mathbf{c m}) \\
M(S D) \\
\text { Range }\end{array}$ & Range of Ranks \\
\hline Artillery & 15 & $29.2(6.2)$ & $87.1(9.5)$ & $184.0(6.2)$ & OR-SNR OFF \\
\hline Armoured & 19 & $\begin{array}{c}20-41 \\
29.8(4.7) \\
21-38\end{array}$ & $\begin{array}{c}65-105 \\
88.1(13.5) \\
62-108\end{array}$ & $\begin{array}{c}172-194 \\
178.8(9.1) \\
155-193\end{array}$ & OR-JNR OFF \\
\hline Engineers* & 93 & $\begin{array}{c}28.4(7.0) \\
18-50\end{array}$ & $\begin{array}{c}83.2(11.6) \\
52-110\end{array}$ & $\begin{array}{c}180.1(7.7) \\
154-200\end{array}$ & OR-SNR OFF \\
\hline Infantry & 99 & $\begin{array}{c}33.1(6.9) \\
22-50\end{array}$ & $\begin{array}{c}87.3(10.5) \\
65-126\end{array}$ & $\begin{array}{c}180.3(7.6) \\
150-198\end{array}$ & OR-SNR OFF \\
\hline Signals* & 27 & $\begin{array}{c}29.2(7.3) \\
21-46\end{array}$ & $\begin{array}{c}77.5(8.1) \\
60-102\end{array}$ & $\begin{array}{c}175.9(7.3) \\
153-187\end{array}$ & OR-SNR OFF \\
\hline Other* & 85 & $\begin{array}{c}34.6(8.3) \\
20-56\end{array}$ & $\begin{array}{c}82.6(13.3) \\
56-116\end{array}$ & $\begin{array}{c}176.4(8.5) \\
154-194\end{array}$ & OR-SNR OFF \\
\hline Combined* & 338 & $\begin{array}{c}31.8(7.8) \\
18-56\end{array}$ & $\begin{array}{c}84.2(11.9) \\
52-126\end{array}$ & $\begin{array}{c}178.9(8.0) \\
150-200\end{array}$ & OR-SNR OFF \\
\hline
\end{tabular}

* includes female members

$\sim$ OR $=$ Other Ranks, JNR OFF $=$ Junior Officer, SNR OFF $=$ Senior Officer 


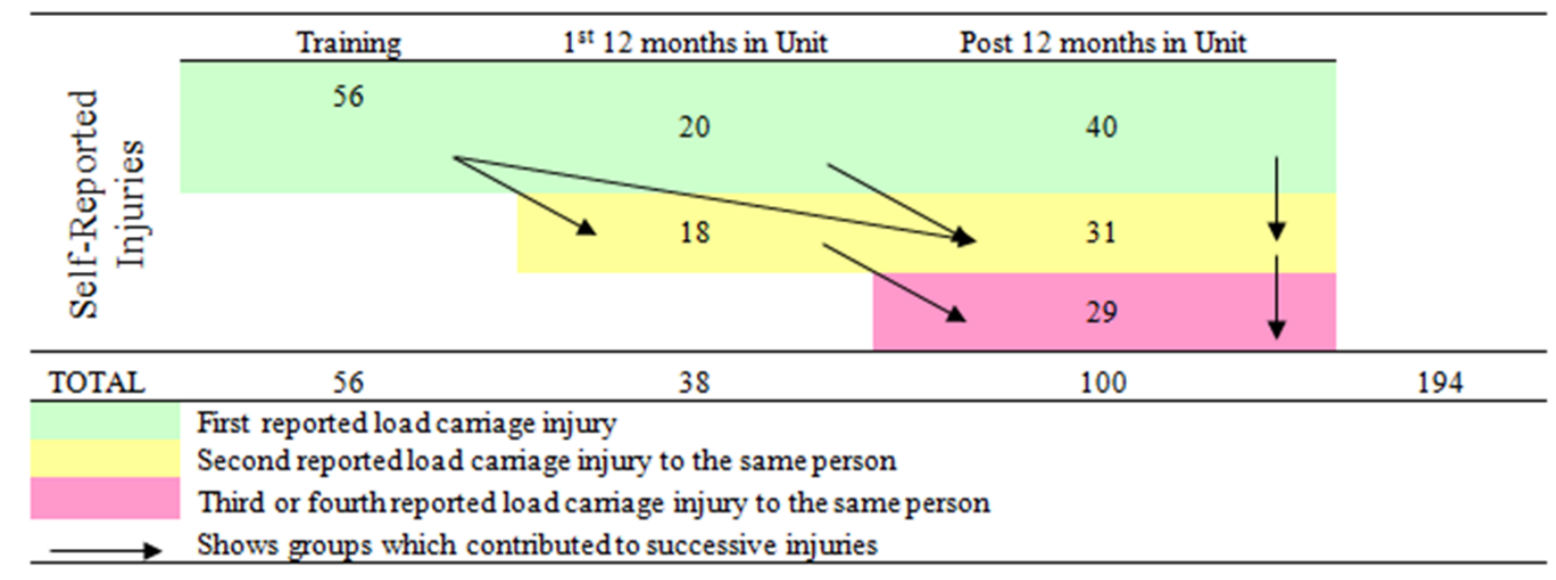

499

500 Figure 2: Histogram of self-reported load carriage injuries by body site.

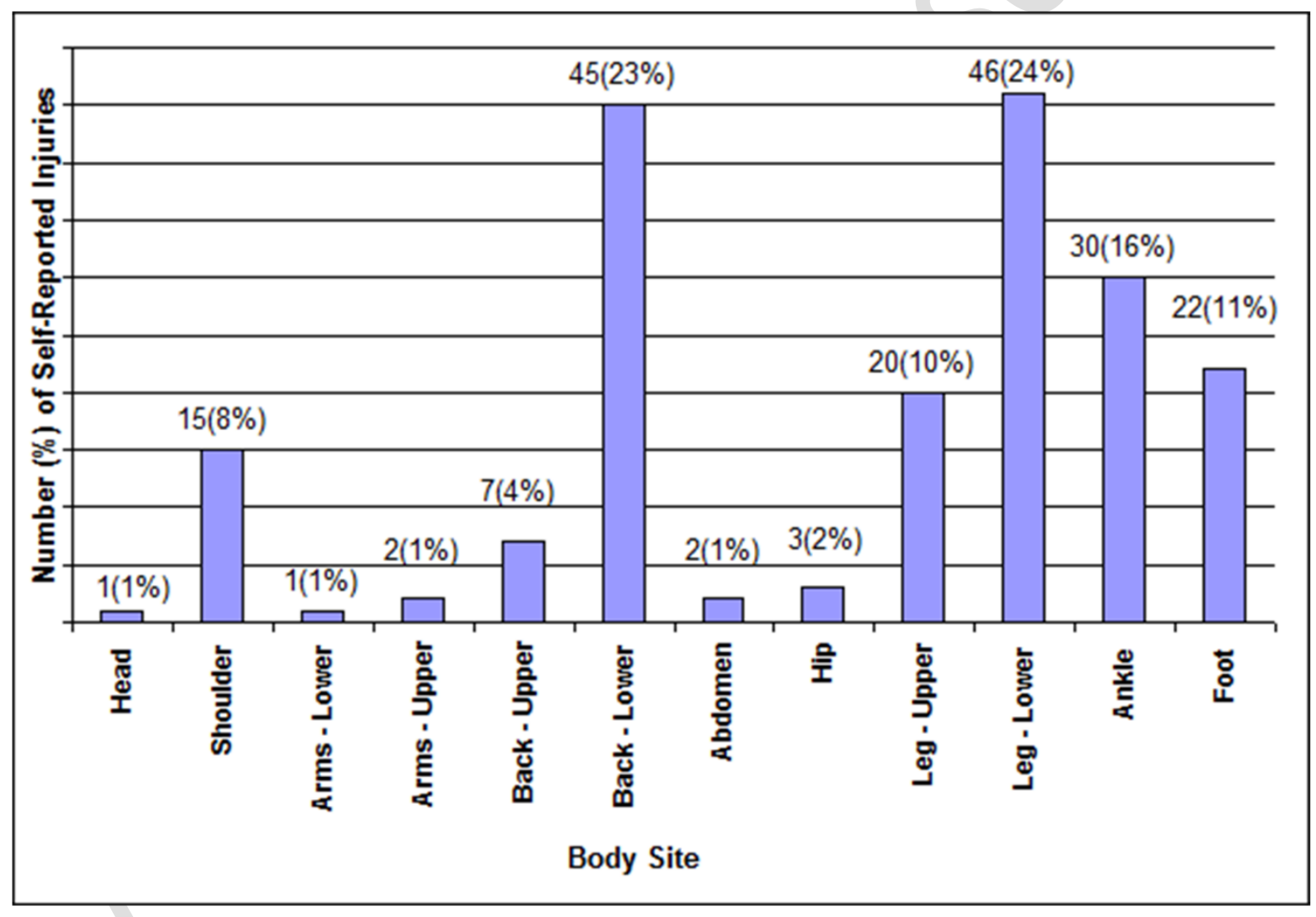


Figure 3: Histogram of self-reported load carriage injuries by nature of injury

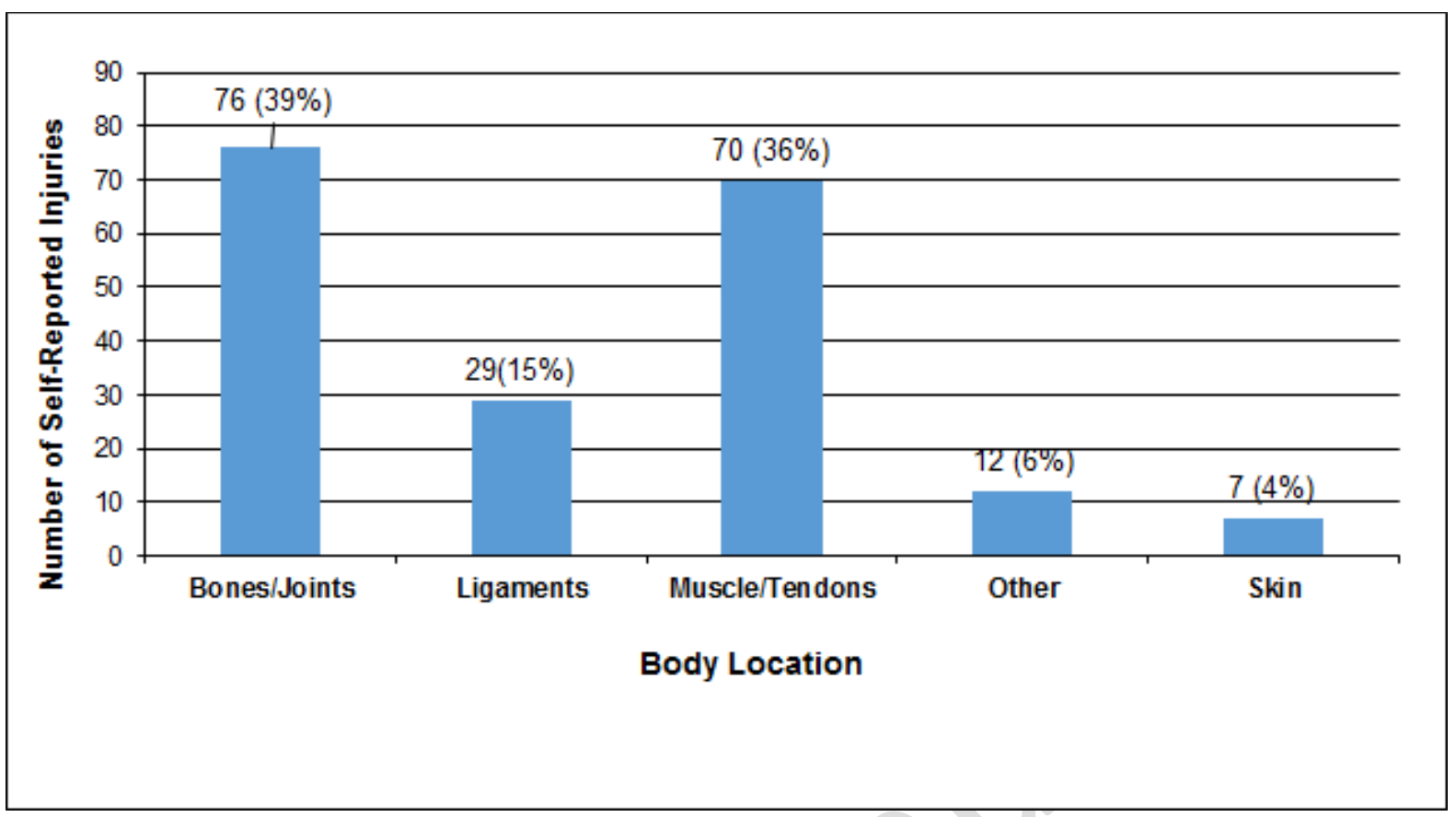

